\title{
Oxidative stress is involved in LLLT mechanism of action on skin healing in rats
}

\author{
D.D. Hartmann ${ }^{1 \oplus \bowtie}$, R.P. Martins ${ }^{1 \oplus}$, T.C. da Silva ${ }^{1 \oplus}$, S.T. Stefanello ${ }^{1 \oplus}$, A.A. Courtes $^{1 \oplus}$, \\ D.F. Gonçalves ${ }^{1 \oplus}$, A.B.V. Furtado ${ }^{1 \oplus}$, B.S.L. Duarte ${ }^{2 \oplus}$, L.U. Signori ${ }^{2 \odot}$, F.A.A. Soares ${ }^{3 \oplus}$, and \\ G.O. Puntel ${ }^{4 \oplus \otimes}$
}

${ }^{1}$ Centro de Ciências Naturais e Exatas, Programa de Pós-Graduação em Ciências Biológicas e Bioquímica Toxicológica, Universidade Federal de Santa Maria, Santa Maria, RS, Brasil

${ }^{2}$ Centro de Ciências da Saúde, Departamento de Fisioterapia, Universidade Federal de Santa Maria, Santa Maria, RS, Brasil

${ }^{3}$ Centro de Ciências Naturais e Exatas, Departamento de Bioquímica e Biologia Molecular, Universidade Federal de Santa Maria, Santa Maria, RS, Brasil

${ }^{4}$ Centro de Ciências da Saúde, Departamento de Morfologia, Universidade Federal de Santa Maria, Santa Maria, RS, Brasil

\begin{abstract}
The skin injury healing process involves the main phases of homoeostasis, inflammation, proliferation, and remodeling. The present study aimed to analyze the effects of low-level laser therapy (LLLT) on hematological dynamics, oxidative stress markers, and its relation with tissue healing following skin injury. Wistar rats were divided into control, sham, skin injury, and skin injury LLLT. The biochemical and morphological analyses were performed in the inflammatory ( 1 and 3 days) and regenerative phases $(7,14$, and 21 days) following injury. The skin injury was performed in the dorsal region, between the intrascapular lines, using a surgical punch. LLLT (AI-Ga-In-P, $\lambda=660 \mathrm{~nm}$, energy density of $20 \mathrm{~J} / \mathrm{cm}^{2}, 30 \mathrm{~mW}$ power, and a time of $40 \mathrm{~s}$ ) was applied at the area immediately after injury and on every following day according to the experimental subgroups. LLLT maintained hematocrit and hemoglobin levels until the 3rd day of treatment. Surprisingly, LLLT increased total leukocytes levels compared to control until the 3rd day. The effects of LLLT on mitochondrial activity were demonstrated by the significant increase in MTT levels in both inflammatory and regenerative phases (from the 1st to the 7th day), but only when associated with skin injury. The results indicated that LLLT modulated the inflammatory response intensity and accelerated skin tissue healing by a mechanism that involved oxidative damage reduction mostly at early stages of skin healing (inflammatory phase).
\end{abstract}

Key words: Rehabilitation; Phototherapy; LLLT; Skin tissue; Inflammation

\section{Introduction}

Skin injuries, or ulcers, are commonly observed in all age groups, but mostly among older adults, those who are immobile and those with severe acute illness or neurological deficits (1). Skin injuries can contribute to further deterioration of one's general health (2). According to the Wound Healing Society, an estimated 2 to 3 million Americans are diagnosed with any type of chronic skin wound each year. Additionally, about $15 \%$ of older adults suffer from chronic wounds, including predominantly venous stasis ulcers, pressure ulcers (bedsores), and diabetic (neuropathic) foot ulcers (3).

One of the most relevant physiological factors related to skin injury pathogenesis is the presence of vascular dysfunction - such as chronic venous insufficiency and/or peripheral arterial occlusive diseases - and sustained hyperglycemia (4). However, hematologic autoimmune, malignant or primary skin diseases, genetic defects, the use of some medications and/or therapeutic procedures, and several exogenous factors can contribute to skin injury etiology $(5,6)$. It is widely accepted that ischemia is a primary factor involved in skin injury genesis and evolution, but it is the blood reflow to ischemic areas that accelerates cell death due to an overproduction of reactive oxygen species (ROS). An increase in ROS levels that exceeds the antioxidant defenses of the skin leads to impairments in cellular biomolecular functions via a mechanism known as oxidative stress (7).

The skin injury healing process is complex and involves four main phases: homoeostasis, inflammation, proliferation (new tissue growth/matrix formation), and tissue remodeling $(8,9)$. The inflammatory phase holds particular importance because an excessive inflammatory response could delay complete tissue healing. Therefore, research on the various techniques that improve the time

Correspondence: D.D. Hartmann:<dianehartmann90@gmail.com> | G.O. Puntel: < gustavopuntel@yahoo.com.br> 
to complete skin healing are of interest to the field of physiotherapy (10). Low-level laser therapy (LLLT) is a phototherapeutic modality that is widely used in clinical practice, and which employs different gas components. Distinct wavelengths are generated and result in different deep tissue targets (as major wavelengths reach deeper areas). The most common LLLTs used are helium/neon (HeNe, $630 \eta \mathrm{m}$ ), aluminium/galium/indium/phosphide (AlGa-In-P, $\lambda=660 \eta \mathrm{m}$ ), gallium/aluminum/arsenide (GaAlAs, 820 and $830 \eta \mathrm{m})$, and gallium/arsenide (GaAs, $904 \eta \mathrm{m}$ ) $(11,12)$.

Previous studies have shown that LLLT contributes to skin injury healing by accelerating wound contraction. This is achieved by increasing fibroblast and epithelium proliferation and also by improving collagen synthesis (13). The effects of LLLT on biological tissues are associated with light radiation absorption by photoacceptors or chromophores located in the mitochondria and hemoglobin of treated areas (11). Houreld et al. (14) reported an increase in cytochrome c oxidase activity as well as an increase in adenosine triphosphate (ATP) synthesis in fibroblasts irradiated with LLLT. Moreover, it was found that LLLT is effective at reducing necrotic areas in the skin possibly due to improvements in cytokine and growth/angiogenic factors' recruitment, as well as enhancement of migration, proliferation, and differentiation of inflammatory cells (12).

Although the benefits of LLLT on skin injury healing have been reported previously, its biological mechanisms of action need to be fully understood. In this study, we first investigated the effects of LLLT on some hematological markers, such as number of blood constituents, to understand treatment effects on the development of the inflammatory response following a skin injury. Knowing that increased ROS formation is expected after skin injury, we also analyzed the effects of LLLT (Al-Ga-In-P, $\lambda=660 \eta \mathrm{m}$ ) on oxidative markers and antioxidant levels in injured/ treated skin areas. Finally, to gain a better understanding of the results, the findings were divided into inflammatory ( 1 and 3 days) or regenerative $(7,14$, and 21 days) phases.

\section{Material and Methods}

\author{
Animals \\ One hundred and twenty male adult Wistar rats \\ weighing 250 to $300 \mathrm{~g}$ were obtained from the Animal \\ Breeding Unit of the Federal University of Santa Maria \\ (UFSM). Animals were allocated in cages with food and \\ water ad libitum and maintained under standard condi- \\ tions of temperature $\left(22 \pm 1^{\circ} \mathrm{C}\right)$ and illumination (12-h light/ \\ dark cycle). The study protocol followed the ethical \\ guidelines established by the Guide for Care and Use of \\ Experimental Animals published by the National Institutes \\ of Health (NIH publication No. 85-23, revised in 1996). All \\ procedures outlined in this study were approved by the \\ Ethics and Research Committee of UFSM (002/2014).
}

\section{Experimental design}

Rats were divided into four experimental groups $(n=120)$, Control (without injury or intervention), Sham (without skin injury with LLLT treatment), Skin injury (without LLLT treatment), and Skin injury + LLLT (with LLLT treatment). The animals were anesthetized with an intraperitoneal injection of ketamine $(10 \%)$ and xylazine $(2 \%)$ administered as $0.1 \mathrm{~mL}$ of solution per $100 \mathrm{~g}$ of body weight.

The dorsal region of each animal was shaved and disinfected with $70 \%$ alcohol. In the left region, between the infrascapular line and the tail, a circular area of skin of approximately $15 \mathrm{~mm}$ diameter and $5 \mathrm{~mm}$ deep was removed with a punch (Groups: Skin injury and Skin injury + LLLT) (15). The skin injuries were uniform in diameter, depth, and location. The right region, used as control (Groups: Control and Sham), was also anesthetized, shaved, and disinfected with $70 \%$ alcohol to ensure standardization (15). After the skin injury, animals were sub-divided in five subgroups according the analysis performed at 1 and 3 days (inflammatory phase) and 7, 14 , and 21 days (regenerative phase) after injury.

\section{Laser application}

Al-Ga-In-P laser (Ibramed, Brazil) with a wavelength of $660 \eta \mathrm{m}$ was applied in a single-point transcutaneous method with an energy density of $20 \mathrm{~J} / \mathrm{cm}^{2}, 30 \mathrm{~mW}$ power, and a time of $40 \mathrm{~s}$. The first LLLT application was performed immediately after injury and repeated once a day every day until euthanasia.

\section{Tissue preparation and analysis}

Rats submitted to the experimental procedures were euthanized with a lethal administration of thiopental (120 mg/kg, ip) at 1, 3, 7, 14, or 21 days after injury. Immediately after euthanasia, a sample of whole blood was collected by cardiac puncture in serum-separating tubes $(5 \mathrm{~mL})$ and another one in tubes containing EDTA $(5 \mathrm{~mL})$ (Vacutainer ${ }^{\mathbb{R}}$, Becton Dickinson, USA).

A sample of skin of each animal $(1 \mathrm{~cm}$ around the injury margin and deep into the subcutaneous fascia) was surgically excised and frozen in liquid nitrogen $\left(-80^{\circ} \mathrm{C}\right)$ until the biochemical analysis.

Skin homogenates were prepared in cold saline $(0.9 \%$ $\mathrm{NaCl}$ ) in a 1:5 (weight:volume) proportion using an Ultra X80 stirrer (Ultra Stirrer, UK). Homogenates were centrifuged at $2,000 \mathrm{~g}$ in $4^{\circ} \mathrm{C}$ for $10 \mathrm{~min}$ to yield the low-speed supernatant (S1) fractions that were used for analysis.

Hematologic analysis. Blood samples collected into tubes containing EDTA (Vacutainer ${ }^{\mathbb{R}}$ ) were used to determine total erythrocytes, hematocrit, hemoglobin, total leucocytes, and platelets using the automatic counter COULTER T890 ${ }^{\mathbb{B}}$ (Coulter Electronics, Inc., USA).

Measurement of lipid peroxidation (LPO). LPO was quantified by malondialdehyde (MDA) formation in skin homogenates (16). In summary, skin homogenates were 
pre-incubated in a medium containing Tris- $\mathrm{HCl}$ as a buffer (10 mM, pH 7.4) for 60 min. Pre-incubation was ended by acetic acid buffer ( $\mathrm{pH} 3.6)$ followed by addition of lauryl sodium sulphate $(8.1 \%$ SDS) and thiobarbituric acid $(0.6 \%$ TBA, pH 6.2). The mixture was incubated at $100^{\circ} \mathrm{C}$ for 60 min until color reaction.

Measurement of ROS production. ROS production in skin homogenates was determined by oxidation of reduced dichlorofluorescein ( $\mathrm{H}_{2}$ DCF-DA) (17). Briefly, skin homogenates were added to standard medium containing Tris$\mathrm{HCl}$ as a buffer (10 mM, pH 7.4) and $\mathrm{H}_{2}$ DCF-DA (1 mM) for $60 \mathrm{~min}$ in a condition without light. Fluorescence quantification was determined at $488 \mathrm{\eta m}$ for excitation and $525 \mathrm{\eta m}$ for emission, with slit widths of $3 \eta \mathrm{m}$, in a spectrofluorometer (RF-5301 PC; Shimadzu, Japan) using oxidized dichlorofluorescein (DCF) as a standard.

Measurement of mitochondrial dehydrogenase activity (MTT reduction assay). This assay is based on the ability of mitochondrial enzymes to metabolize MTT into formazan, a reaction that takes place only in functionally intact mitochondria, determined by methyl tetrazolium salt (MTT) reduction (18). Briefly, skin homogenates were preincubated with MTT at $30^{\circ} \mathrm{C}$ for $60 \mathrm{~min}$. Dimethyl sulphoxide ( $1 \mathrm{~mL}$ DMSO) was added to extract colored components and measurements were made at $570 \mathrm{\eta m}$. Results are reported in percent of the control (skin samples without injury and without LLLT) values.

Measurement of antioxidant enzyme activities. The antioxidant enzymes total superoxide dismutase (SOD) and catalase (CAT) were measured as described previously $(19,20)$ in skin homogenates. For SOD analysis, the skin homogenate was added to a medium containing ethylenediamine tetraacetic acid ( $2 \mathrm{mM}$ EDTA) and bicarbonate buffer $\left(50 \mathrm{mM} \mathrm{NaHCO} / \mathrm{Na}_{2} \mathrm{CO}_{3}, \mathrm{pH}\right.$ 10.3). Epinephrine (4 $\mathrm{mM})$ was added to start the kinetic SOD activity for $5 \mathrm{~min}$. The colored product of epinephrine degradation (that was inhibited by cellular SOD activity) was spectrophotometrically measured at $480 \eta \mathrm{m}$. The SOD enzyme activity is reported in units of the enzyme activity per milligrams of protein. For CAT assay, skin homogenate was added to a medium containing potassium phosphate buffer (50 mM KH $\mathrm{PO}_{4}, 50 \mathrm{mM} \mathrm{K}_{2} \mathrm{HPO}_{4}$; $\mathrm{pH}$ 7.4). The kinetic analysis of CAT was started after hydrogen peroxide $\left(1 \mathrm{mM} \mathrm{H}_{2} \mathrm{O}_{2}\right)$ addition. The CAT activity was determined using the molar extinction coefficient $36 \mathrm{M}^{-1} \mathrm{~cm}^{-1}$ and the reaction was spectrophotometrically measured at $240 \eta \mathrm{m}$.

Non-protein thiol (NPSH) measurement. NPSH levels were determined in skin homogenates according to the method proposed previously (21) with some modifications. Briefly, homogenate samples were precipitated with TCA (5\%) $(1: 1)$ and subsequently centrifuged at $4,000 \mathrm{~g}$ for $10 \mathrm{~min}$ at $4^{\circ} \mathrm{C}$. Supernatant fraction $(500 \mu \mathrm{L})$ was added to a reaction medium containing $\mathrm{K}$-phosphate buffer (0.25 mM, pH 7.4) and DTNB (1 mM). Spectrophotometrical measurements were made at $412 \eta \mathrm{m}$. Results were calculated in relation to a standard curve constructed with GSH (reduced glutathione) at known concentrations and corrected by the protein content.

Protein measurement. Protein content was determined using bovine serum albumin (BSA) as the standard according to a previous study (17). Spectrophotometrical measurements were made at $595 \mathrm{\eta m}$.

\section{Statistical analysis}

Statistical analysis was performed using GraphPad (version 5.0 for Macintosh OSX, USA). The distribution of variables was tested using the Kolmogorov-Smirnov normality test. Significance was assessed by two-way analysis of variance (ANOVA), followed by Bonferroni test for post hoc comparison. Differences were significant when $\mathrm{P}<0.05$.

\section{Results}

\section{Effects of LLLT on hematological dynamics of the inflammatory phase}

Hematocrit and hemoglobin demonstrated significant differences when exploring the injury $\times$ LLLT interaction $\left(F_{(1,6)}=18.90, P<0.05\right)$. Three days following the skin injury, hematocrit $(\mathrm{P}<0.05,95 \% \mathrm{Cl}=-15.70$ to -3.963$)$ and hemoglobin levels $(P<0.05,95 \% \mathrm{Cl}=-5.308$ to -1.062$)$ decreased compared to day 1 in the Skin injury group. Treatment with LLLT was effective against this decrease in hematocrit $(\mathrm{P}<0.05,95 \% \mathrm{Cl}=4.496$ to 16.24$)$ and hemoglobin levels $(P<0.05,95 \% \mathrm{Cl}=1.129$ to 5.374$)$ (Table 1$)$.

A significant interaction was found in erythrocytes in the inflammatory phase for injury $\times \operatorname{LLLT}\left(F_{(1,6)}=10.22\right.$, $\mathrm{P}=0.0187$ ); however, Table 1 shows that neither injury nor treatment with LLLT caused a significant difference in erythrocyte count.

In the early stages of wound healing, the leucocytes presented a significant main effect of time $\left(F_{(1,6)}=21.34\right.$, $\mathrm{P}=0.0036)$ and $\operatorname{LLLT}\left(\mathrm{F}_{(1,6)}=66.53, \mathrm{P}<0.001\right)$. LLLT was associated with increased leucocyte count on the first day compared to the Skin injury group $(\mathrm{P}<0.05,95 \% \mathrm{Cl}=1.961$ to 7.439). Nevertheless, on the third day, the Control group and the LLLT group demonstrated a reduction in leucocyte count compared to the first day $(\mathrm{P}<0.05,95 \% \mathrm{Cl}=1.805$ to 7.862 and $95 \% \mathrm{Cl}=3.905$ to 9.962 , respectively).

An examination of the platelet count revealed a significant injury $\times$ LLLT interaction $\left(F_{(1,6)}=18.06, P=0.0054\right)$. The Skin injury group had a significant decrease in platelet levels on the 3rd day compared to the first day $(P<0.05$, $95 \% \mathrm{Cl}=238.8$ to 509.7 ), and LLLT was effective against this decrease, as it helped to maintain these levels (Table 1).

\section{Effects of LLLT on skin oxidative damage in the inflammatory phase}

Figure $1 \mathrm{~A}$ shows that thiobarbituric acid reactive substances (TBARS) had a significant injury $\times$ laser interaction $\left(F_{(3,20)}=8,427, P<.0008\right)$. The Skin injury group 
Table 1. Effects of low-level laser therapy (LLLT) on red and white blood cells in the inflammatory phase.

\begin{tabular}{|c|c|c|c|c|c|c|}
\hline \multirow[t]{2}{*}{ Hematological variable } & \multirow[t]{2}{*}{ Group (n, 4) } & \multicolumn{2}{|c|}{ Collections } & \multicolumn{3}{|c|}{$P$ value (ANOVA) } \\
\hline & & Day 1 & Day 3 & Treatment & Time & Interactions \\
\hline \multirow[t]{2}{*}{ Hematocrit (g/dL) } & Control & $37.0 \pm 5.0$ & $27.0 \pm 7.4^{\mathrm{a}}$ & 0.1351 & $0.0045^{*}$ & $0.0048^{*}$ \\
\hline & LLLT & $37.6+1.2$ & $37.5 \pm 3.1^{*}$ & & & \\
\hline \multirow[t]{2}{*}{ Erythrocytes $\left(\times 10^{6} / \mu \mathrm{L}\right)$} & Control & $6.6 \pm 0.5$ & $5.6 \pm 1.9$ & 0.4264 & 0.5173 & $0.0187^{*}$ \\
\hline & LLLT & $6.2 \pm 1.1$ & $7.04 \pm 0.7$ & & & \\
\hline \multirow[t]{2}{*}{ Hemoglobin (g/dL) } & Control & $12.4 \pm 1.6$ & $9.2 \pm 2.3^{a}$ & 0.1213 & $0.0017^{*}$ & $0.0047^{*}$ \\
\hline & LLLT & $12.8 \pm 0.3$ & $12.5 \pm 1.0^{*}$ & & & \\
\hline \multirow[t]{2}{*}{ Leukocytes $\left(\times 10^{3} / \mu \mathrm{L}\right)$} & Control & $10.0 \pm 1.1$ & $5.2 \pm 0.7^{a}$ & $0.0036^{*}$ & $0.0002^{*}$ & 0.1957 \\
\hline & LLLT & $14.7 \pm 0.5^{\star}$ & $7.8 \pm 2.6^{a}$ & & & \\
\hline \multirow[t]{2}{*}{ Platelets $\left(\times 10^{3} / \mu \mathrm{L}\right)$} & Control & $756.2 \pm 132.1$ & $384.0 \pm 34.2^{a}$ & 0.2459 & $0.0003^{*}$ & $0.0054^{*}$ \\
\hline & LLLT & $566.2 \pm 64.0$ & $466.2 \pm 13.4$ & & & \\
\hline
\end{tabular}

Data are reported as means $\pm \mathrm{SE} .{ }^{*} \mathrm{P}<0.05$ compared to Control group; ${ }^{\mathrm{a}} \mathrm{P}<0.05$ compared to values of day 1 in the same experimental group (two-way ANOVA followed by post hoc Bonferroni test).
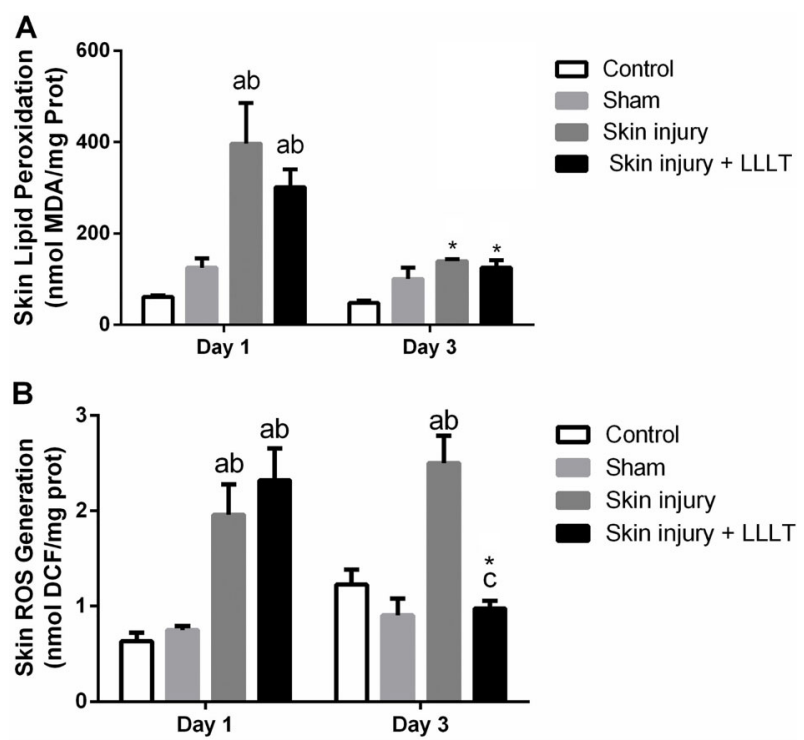

Figure 1. Effects of low-level laser therapy (LLLT) $(660 \eta \mathrm{m})$ on skin oxidative damage markers in the inflammatory phase. A, Lipid peroxidation (TBARS) and (B) reactive species production (oxidized DCF) levels. Data are reported as means $\pm \mathrm{SE}$. ${ }^{*} \mathrm{P}<0.05$ compared to day 1 in the same experimental group; ${ }^{a} \mathrm{P}<0.05$ compared to Control group $(\mathrm{P}<0.05) ;{ }^{\mathrm{b}} \mathrm{P}<0.05$ compared to Sham group; ${ }^{C} \mathrm{P}<0.05$ compared to Skin injury group (ANOVA followed by post hoc Bonferroni test). ROS: reactive oxygen species.

had higher lipid peroxidation levels on the first day compared to the Control $(\mathrm{P}<0.0001,95 \% \mathrm{Cl}=239.3$ to 498.4) and Sham groups $(\mathrm{P}<0.0001,95 \% \mathrm{Cl}=175.5$ to 434.6). Treatment with LLLT decreased lipid peroxidation levels. In addition, on the third day, Skin injury and Skin injury + LLLT showed a reduction in the lipid peroxidation levels compared to the first day $(\mathrm{P}<0.001,95 \% \mathrm{Cl}=-399.0$ to $-115.4 ; \mathrm{P}<0.05,95 \% \mathrm{Cl}=-317.8$ to -34.28 , respectively).

ROS levels showed a significant injury $\times$ laser interaction $\left(F_{(3,19)}=7.731, P=0.0014\right)$. On day 1 , the Skin injury group had higher mitochondrial ROS levels compared to those of the Control group $(P<0.001,95 \%$ $\mathrm{Cl}=0.5099$ to 2.142$)$ and the Sham group $(\mathrm{P}<0.01,95 \%$ $\mathrm{Cl}=0.3919$ to 2.024); LLLT was not effective against this increase. Nevertheless, LLLT significantly reduced the ROS levels on day 3 compared to day 1 ( $P<0.05,95 \%$ $\mathrm{Cl}=-2.71$ to -0.4206 ), and it was found to be effective in relation to the increase resulting from the skin injury $(\mathrm{P}<0.001,95 \% \mathrm{Cl}=-2.382$ to -0.6698$)$ (Figure 1B).

\section{Effects of LLLT on mitochondrial dehydrogenase activity in the inflammatory phase}

Dehydrogenase activity showed a significant main effect of treatment $\left(F_{(3,24)}=7.961, P=0.0007\right)$. On the first day, the Skin injury + LLLT group had increased dehydrogenase activity compared to the Control $(P<0.001,95 \%$ $\mathrm{Cl}=28.47$ to 126.1$)$ and Skin injury groups $(\mathrm{P}<0.0001$, $95 \% \mathrm{Cl}=40.62$ to 138.3 ). However, by day 3 , LLLT was effective at maintaining this increase compared to the activity noted on day $1(\mathrm{P}<0.05,95 \% \mathrm{Cl}=-92.23$ to -4.938$)$ (Figure 2).

\section{Effects of LLLT on skin enzymatic and non-enzymatic antioxidants in the inflammatory phase}

SOD activity results revealed a significant injury $\times$ laser interaction $\left(F_{(3,20)}=3.452, P=0.036\right)$. On the first day, the Skin injury group had increased SOD activity compared to the Control $(\mathrm{P}<0.05,95 \% \mathrm{Cl}=7.804$ to 18.10$)$, Sham ( $P<0.05,95 \% \mathrm{Cl}=9.727$ to 20.03 ), and Skin injury + LLLT groups $(\mathrm{P}<0.05,95 \% \mathrm{Cl}=-13.20$ to -2.896$)$. The Skin injury group maintained greater SOD activity during 3 days compared to the Control $(\mathrm{P}<0.05,95 \% \mathrm{Cl}=4.799$ to 15.10$)$ and Sham groups on the first day $(\mathrm{P}<0.05,95 \% \mathrm{Cl}=1.321$ to 11.62). On the third day, LLLT promoted an increase in SOD activity compared to the Control group $(P<0.05$, $95 \% \mathrm{Cl}=1.414$ to 11.71 ) (Figure $3 \mathrm{~A}$ ).

Figure $3 B$ shows the effect of the LLLT-altered nonprotein thiol levels in the skin, which demonstrated a 


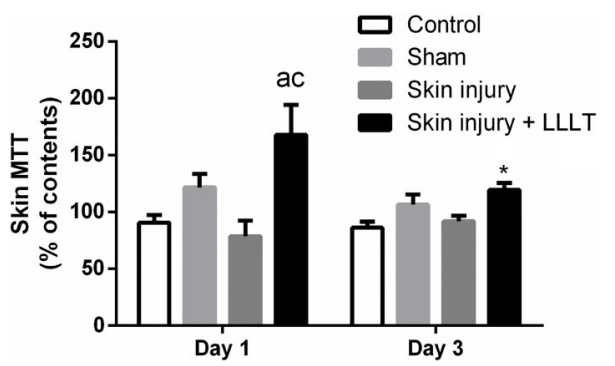

Figure 2. Effects of low-level laser therapy (LLLT) (660 ๆm) on skin cell viability (MTT reduction levels) in the inflammatory phase. Data are reported as means \pm SE. ${ }^{*} P<0.05$ compared to day 1 in the same experimental group; ${ }^{\text {ap }}<0.05$ compared to Control group $(\mathrm{P}<0.05){ }^{\mathrm{C}} \mathrm{P}<0.05$ compared to Skin injury group (ANOVA followed by post hoc Bonferroni test).
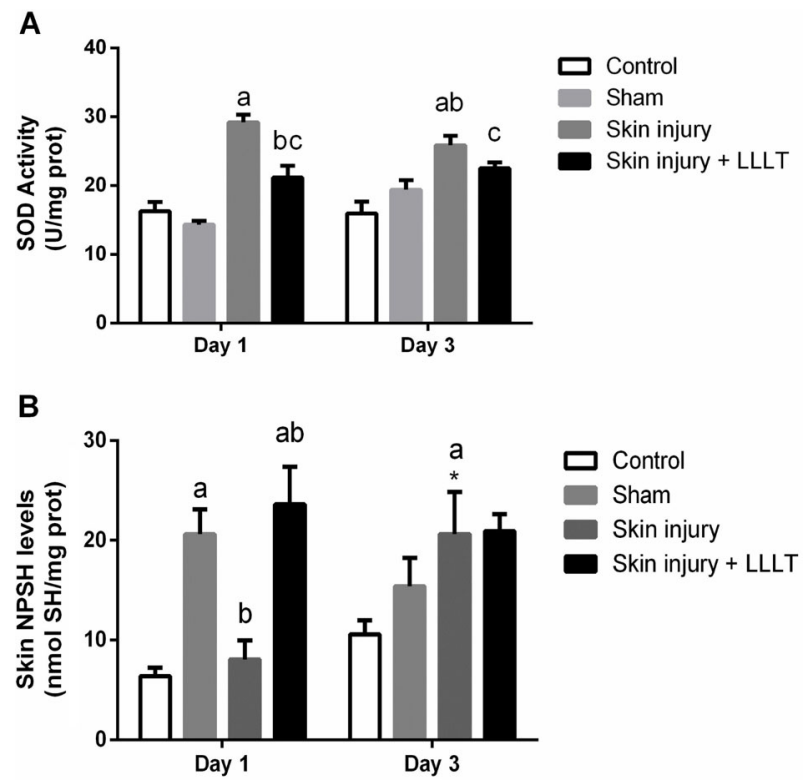

Figure 3. Effects of low-level laser therapy (LLLT) (660 ๆm) on skin antioxidants in the inflammatory phase. A, Superoxide dismutase enzyme activity (SOD) and (B) non-protein thiol levels (NPSH). Data are reported as means $\pm \mathrm{SE}$. ${ }^{*} \mathrm{P}<0.05$ compared to day 1 in the same experimental group; ${ }^{a} \mathrm{P}<0.05$ compared to Control group $(P<0.05)$; ${ }^{b} P<0.05$ compared to Sham group; ${ }^{\mathrm{c}} \mathrm{P}<0.05$ compared to Skin injury group (ANOVA followed by post hoc Bonferroni test).

significant main effect of laser $\left(F_{(3,20)}=4.288, P=0.0172\right)$ and treatment $\left(F_{(3,20)}=10.67, P=0.0002\right)$. There was no change in the NPSH levels in the Skin injury group on the first day compared to the Control group, although LLLT promoted NPSH level increases in the Sham $(\mathrm{P}<0.001$, $95 \% \mathrm{Cl}=-22.87$ to -2.238 ) and Skin injury + LLLT groups $(\mathrm{P}<0.001,95 \% \mathrm{Cl}=5.240$ to 25.88$)$ compared to the Skin injury group. After 3 days, the Skin injury group showed an increase in NPSH levels compared to day $1(\mathrm{P}<0.05$, $95 \% \mathrm{Cl}=2.019$ to 23.16 ).

\section{Effects of LLLT on the hematological dynamics of the regeneration phase}

In the regeneration phase, erythrocyte counts presented a significant main effect of time $\left(F_{(1,6)}=13.48\right.$; $P=0.0009$ ). Similarly, hematocrit and hemoglobin demonstrated significant main effects of time $\left(F_{(1,6)}=20.58\right.$, $\mathrm{P}<0.001 ; F_{(1,6)}=26.41, P<0.001$, respectively) (Table 2). Neither the Skin injury group nor Skin injury + LLLT group presented significant differences.

Leucocyte counts revealed a significant main effect of time $\left(F_{(1,6)}=5.902, P=0.0162\right)$ in the regeneration phase. The Skin injury group presented a reduction in leucocyte levels within 7 days, and LLLT was effective against this decrease $(\mathrm{P}<0.05,95 \% \mathrm{Cl}=1.805$ to 7.862$)$ (Table 2$)$.

Platelet counts showed a significant injury $\times$ laser interaction $\left(F_{(1,6)}=3.306, P=0.0038\right)$. The Skin injury group had increased platelet levels on days $14(\mathrm{P}<0.05,95 \%$ $\mathrm{Cl}=53.35$ to 228.6$)$ and $21(\mathrm{P}<0.05,95 \% \mathrm{Cl}=120.4$ to 295.6) compared to day 7. The LLLT increased the platelet levels at 14 days compared to 7 days $(\mathrm{P}<0.05,95 \%$ $\mathrm{Cl}=21.60$ to 196.9$)$, as well as at 21 days compared to 14 days $(\mathrm{P}<0.05,95 \% \mathrm{Cl}=78.35$ to 253.6). Thus, LLLT promoted a gradient increase in platelet levels compared to the Skin injury group at 14 days $(\mathrm{P}<0.05,95 \% \mathrm{Cl}=$ -248.1 to -49.94 ) (Table 2).

\section{Effects of LLLT on skin oxidative damage in the regeneration phase}

In the regenerative phase, TBARS showed a significant effect of time $\left(F_{(3,20)}=3.924, P=0.0277\right)$. On the seventh day, the Skin injury group demonstrated a sustained increase in lipid peroxidation levels compared to the Control group ( $\mathrm{P}<0.05,95 \% \mathrm{Cl}=19.09$ to 150.2$)$, and LLLT was effective against this increase $(P<0.001,95 \%$ $\mathrm{Cl}=-1.627$ to -0.4491 ) (Figure 4A).

Only at day 14 did the Skin injury group demonstrate a reduction in lipid peroxidation levels compared to day 7 $(\mathrm{P}<0.001,95 \% \mathrm{Cl}=-136.7$ to -15.99$)$. This was maintained until day $21(\mathrm{P}<0.001,95 \% \mathrm{Cl}=-136.7$ to -15.99$)$ (Figure 4A).

The ROS levels showed a significant main effect of time $\left(F_{(3,19)}=25.26, P=0.0001\right)$ and $\operatorname{LLLT}\left(F_{(3,19)}=10.21\right.$; $P=0.0003)$. The Skin injury group showed an increase in ROS levels compared to the Control $(P<0.0001$, $95 \% \mathrm{Cl}=0.5767$ to 1.755$)$ and Sham groups $(P<0.001$, $\mathrm{Cl}=0.1374$ to 1.315$)$, and LLLT was effective against this increase $(\mathrm{P}<0.001,95 \% \mathrm{Cl}=-1.627$ to -0.4491$)$. Furthermore, the Skin injury group showed a reduction in ROS levels on day 14 compared to day 7 ( $P<0.001$, $95 \% \mathrm{Cl}=-1.627$ to -0.4491$)$; this effect was sustained until 21 days $(\mathrm{P}<0.001,95 \% \mathrm{Cl}=-1.544$ to -0.4829$)$ (Figure 4B). 
Table 2. Effects of low-level laser therapy (LLLT) on red and white blood cells in the regenerative phase.

\begin{tabular}{|c|c|c|c|c|c|c|c|}
\hline \multirow[t]{2}{*}{ Hematological variable } & \multirow[t]{2}{*}{ Group $(n, 4)$} & \multicolumn{3}{|c|}{ Collections } & \multicolumn{3}{|c|}{$P$ value (ANOVA) } \\
\hline & & Day 7 & Day 14 & Day 21 & Treatment & Time & Interactions \\
\hline \multirow[t]{2}{*}{ Hematocrit (g/dL) } & Control & $31.4 \pm 4.8$ & $32.5 \pm 3.7$ & $39.4 \pm 0.4$ & 0.4767 & $0.0001^{*}$ & 0.3567 \\
\hline & LLLT & $34.7 \pm 0.9$ & $31.6 \pm 3.3$ & $40.3 \pm 1.1$ & & & \\
\hline \multirow[t]{2}{*}{ Erythrocytes $\left(\times 10^{6} / \mu \mathrm{L}\right)$} & Control & $6.0 \pm 0.9$ & $6.1 \pm 0.7$ & $7.2 \pm 0.02$ & 0.6893 & $0.0009^{*}$ & 0.6694 \\
\hline & LLLT & $6.3 \pm 0.3$ & $5.9 \pm 0.6$ & $7.4 \pm 0.1$ & & & \\
\hline \multirow[t]{2}{*}{$\mathrm{Hgb}(\mathrm{g} / \mathrm{dL})$} & Control & $10.2 \pm 1.7$ & $11.0 \pm 1.2$ & $13.3 \pm 0.2$ & 0.242 & $<0.0001^{*}$ & 0.136 \\
\hline & LLLT & $11.8 \pm 0.4$ & $11.1 \pm 0.4$ & $13.4 \pm 0.3$ & & & \\
\hline \multirow[t]{2}{*}{ Leukocytes $\left(\times 10^{3} / \mu \mathrm{L}\right)$} & Control & $6.4 \pm 0.3$ & $8.1 \pm 1.9$ & $9.5 \pm 1.1$ & 0.8776 & $0.0181^{*}$ & 0.3888 \\
\hline & LLLT & $7.4 \pm 0.9^{*}$ & $7.7 \pm 2.9$ & $8.9 \pm 0.7$ & & & \\
\hline \multirow[t]{2}{*}{ Platelets $\left(x 10^{3} / \mu \mathrm{L}\right)$} & Control & $538.5 \pm 38.8$ & $746.5 \pm 88.5^{\mathrm{a}}$ & $679.5 \pm 3.6^{a}$ & $0.0337^{*}$ & $<0.0001^{*}$ & $0.0389^{*}$ \\
\hline & LLLT & $488.2 \pm 19.6$ & $597.5 \pm 82.8^{\star a}$ & $654.2 \pm 16.7^{a}$ & & & \\
\hline
\end{tabular}

Data are reported as means $\pm \mathrm{SE} .{ }^{*} \mathrm{P}<0.05$ compared to Control group; ${ }^{\mathrm{a}} \mathrm{P}<0.05$ compared to values of day 7 in the same experimental group (two-way ANOVA followed by post hoc Bonferroni test).
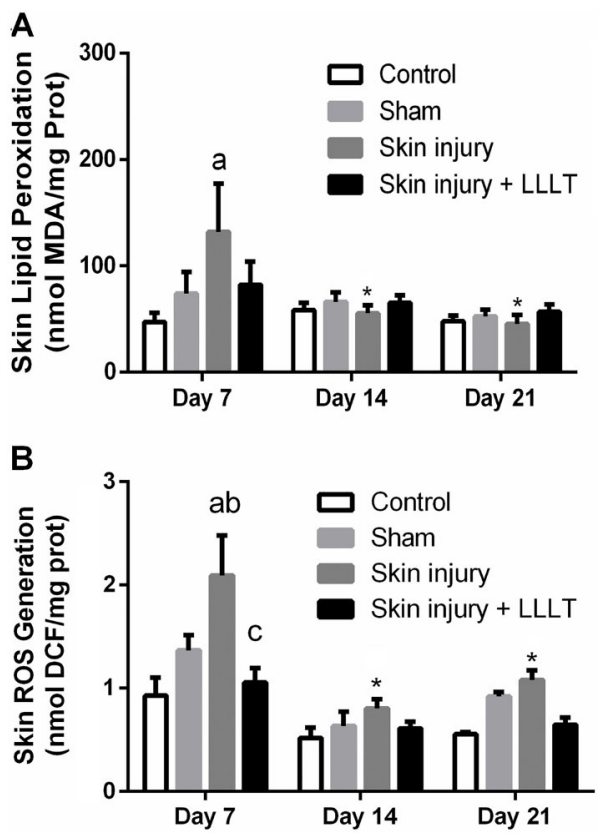

Figure 4. Effects of low-level laser therapy (LLLT) $(660 \eta \mathrm{m})$ on skin oxidative damage markers in the regenerative phase. A, Lipid peroxidation (TBARS) and (B) reactive oxygen species (ROS) production (oxidized DCF) levels. Data are reported as means $\pm S E .{ }^{*} P<0.05$ compared to day 7 in the same experimental group; ${ }^{a} \mathrm{P}<0.05$ compared to Control group $(\mathrm{P}<0.05)$; ${ }^{\mathrm{b}} \mathrm{P}<0.05$ compared to Sham group; ${ }^{\mathrm{C}} \mathrm{P}<0.05$ compared to Skin injury group (ANOVA followed by post hoc Bonferroni test).

\section{Effects of LLLT on mitochondrial dehydrogenase activity in the regeneration phase}

Dehydrogenase activity showed a significant main effect of LLLT $\left(F_{(3,24)}=3.062, P=0.0474\right)$. Skin injury + LLLT had increased MTT levels compared to the Control $(\mathrm{P}<0.05,95 \% \mathrm{Cl}=1.500$ to 80.07$)$ and Skin injury groups $(\mathrm{P}<0.0376,95 \% \mathrm{Cl}=1.500$ to 80.07$)$ (Figure 5).

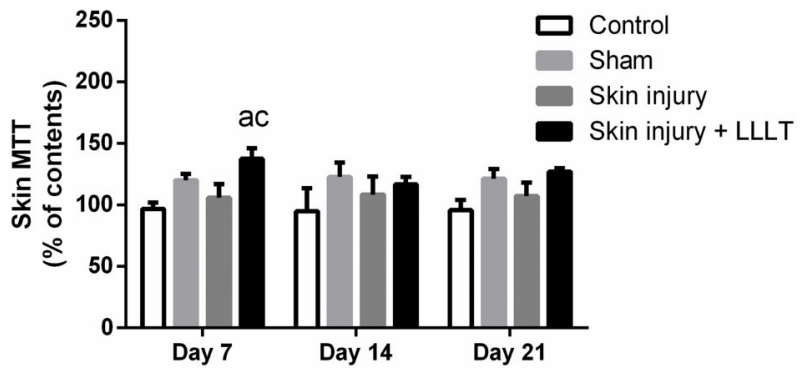

Figure 5. Effects of low-level laser therapy (LLLT) (660 ๆm) on skin cell viability (MTT reduction levels) in the regenerative phase. Data are reported as means $\pm \mathrm{SE}$. ${ }^{\mathrm{a}} \mathrm{P}<0.05$ compared to Control group $(P<0.05) ;{ }^{c} P<0.05$ compared to Skin injury group (ANOVA followed by post hoc Bonferroni test).

\section{Effects of LLLT on skin enzymatic and non-enzymatic} antioxidants in the regeneration phase

SOD activity showed a significant main effect of LLLT $\left(F_{(3,20)}=4.338, P=0.0165\right)$. On day 7 , the Skin injury + LLLT group demonstrated decreased SOD activity compared to the Sham group $(\mathrm{P}<0.05,95 \% \mathrm{Cl}=-8.261$ to $-0.8038)$.

LLLT alone (Sham group) exhibited decreased SOD activity at 14 days compared to day $7(\mathrm{P}<0.05,95 \% \mathrm{Cl}=$ -6.677 to -0.8078$)$. The Skin injury + LLLT group also showed a decrease in this enzymatic activity compared to the Skin injury group on day $14(\mathrm{P}<0.05,95 \% \mathrm{Cl}=-7.663$ to -0.2053 ) (Figure 6A).

Neither skin injury nor treatment promoted a significant change in non-protein thiol levels in the skin (Figure 6B).

\section{Discussion}

We explored the effect of LLLT on its ability to reduce the oxidative stress in skin homogenate and to alter the blood parameters in rats. We used LLLT, a well-known 

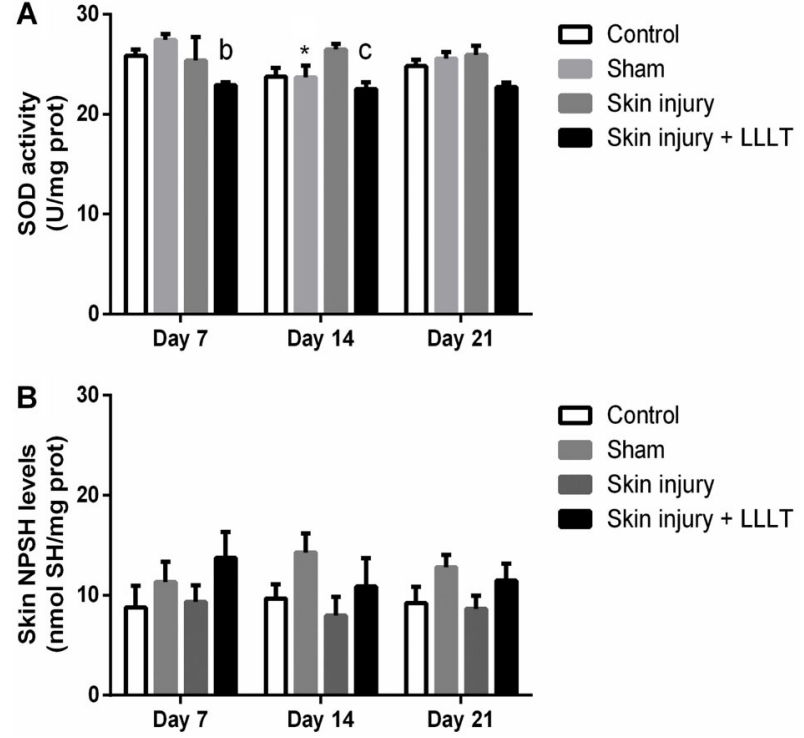

Figure 6. Effects of low-level laser therapy (LLLT) $(660 \eta \mathrm{m})$ on skin antioxidants in the regenerative phase. A, Superoxide dismutase enzyme activity (SOD) and (B) non-protein thiol levels (NPSH). SOD values are reported in units of enzyme activity per $\mathrm{mg}$ of protein. Data are reported as means $\pm \mathrm{SE}$. ${ }^{*} \mathrm{P}<0.05$ compared to day 7 in the same experimental group; ${ }^{\mathrm{b}} \mathrm{P}<0.05$ compared to Sham group; ${ }^{\mathrm{P}}<0.05$ compared to Skin injury group (ANOVA followed by post hoc Bonferroni test).

intervention for skin injury, to better understand the effects in different phases of cellular healing. To the best of our knowledge, this is the first study to demonstrate that LLLT maintained hematocrit and hemoglobin levels until the third day of treatment (leukocyte levels increased on the first day). In fact, LLLT increased the total leukocyte levels compared to the control until day 3 . This result was in accordance with the observations made by Boschi et al. (22), who conducted a study using LLLT $\left(21 \mathrm{~J} / \mathrm{cm}^{2}\right)$ for 1 , 2 , and $3 \mathrm{~h}$ following carrageenan injection. Machneva et al. (23) also reported an increase in leukocyte activity in association with red laser radiation in animals injected with lipopolysaccharides. Leukocytes, edema, and other hematological parameters are considered the key players of the inflammatory response (24). Taken together, the hematological results suggested that LLLT anticipated inflammatory cell recruitment to the injured area, thus enhancing the healing process in Wistar rats.

Energy absorption is the primary mechanism that enables light from the laser to produce biological effects in tissue. Light absorption is dependent on wavelength, and the main tissue chromophores - such as hemoglobin and melanin - strongly absorb wavelengths shorter than $600 \mathrm{~nm}$ (11). LLLT demonstrated the efficiency of therapeutic light, as it was able to maintain hematocrit and hemoglobin levels in the inflammatory phase.
The specific mechanism underlying the action of light at the cellular level is based on photobiological reactions, which mediate the biological effects. A photobiological reaction is when photoreceptor molecules absorb a specific wavelength of light (11). A previous study reported that LLLT increases ATP synthesis after $3 \mathrm{~min}$ of irradiation (25). Karu et al. (26) reported increases in ATP synthesis induced by LLLT in human cervical cancer (HeLa) cells, but only after 20-25 min of irradiation. Other studies have reported the dose-dependent effects of LLLT on mitochondria, such as increases in mitochondrial membrane potential (MMP) (27) and in mitochondrial complex IV activity (cytochrome c oxidase) (14). In fact, the primary reactions underlying light activity on the photoreceptors have not yet been clearly established, but some hypotheses have been put forward (11). It is believed that mitochondrial complex IV activation is the basic biological mechanism responsible for the effects of LLLT, as it is considered the major site of light issued by LLLT absorption (28-30).

Our findings demonstrated that the effects of LLLT on mitochondrial activity showed significant increases in dehydrogenase enzyme activity, mainly located in mitochondria (18) (MTT levels) in inflammatory and regenerative phases (from days 1 to 7 ). This result is aligned with the findings of Volpato et al. (31), who reported an increase in MTT levels with LLLT treatment in fibroblasts after $72 \mathrm{~h}$. Considering that an increased reduction in MTT levels is associated with higher dehydrogenase enzyme activity in the mitochondria, it is possible that LLLT may improve the mitochondrial activity of skin-treated areas.

Mitochondria are primarily involved in the regulation of cell proliferation, ATP generation, cell death, and metabolism (26). Nevertheless, this organelle was recently identified as a central factor involved in the control of innate immunity and the inflammatory response, while the intrinsic dynamicity of the mitochondrial compartment plays a central role in proinflammatory signaling (32). In addition, previous studies already associated LLLT with increased electron flux through the mitochondrial transport chain $(33,34)$. It is interesting to note that the increase in dehydrogenases enzyme activities was observed only when LLLT was associated with skin injury.

The importance of ATP in the inflammation phase has been established. Specifically, ATP released from stressed cells functions as a "danger" and "find-me" signal for phagocytes to migrate to the damaged tissue (35). During the inflammation phase, ATP may be released by activated platelets and leukocytes. In the same way, the mitochondria constitute a major source of ROS production, while mitochondrial complex activity helps in the electron escape (36). Following the application of LLLT, cytochrome c oxidase becomes electrically charged, from which it alters its redox status and causes an increase in electron transfer in the respiratory chain. 
This then enables an increase in the production of superoxide anion (11).

In fact, skin injury significantly increased oxidative damage markers (lipid peroxidation) until day 7 , and it also increased ROS generation in the inflammatory and regenerative phases. ROS overproduction triggers oxidative damage (including lipid peroxidation) and alters the mitochondrial membrane potential that results in extensive oxidative damage and cell death. In addition, the tissue repair process consists of several interdependent phases: degeneration, inflammation, regeneration, fibrosis/scar formation, and remodeling $(8,9)$. Evidence has suggested that uncontrolled ROS generation plays an important role in the formation of fibroses. This phase usually occurs around 14 days after injury, reaching its peak at 21 days, as characterized by the synthesis and deposition of collagen (37).

However, LLLT exhibits this profile only during the inflammatory phase, and mostly on the first day. LLLT was reported to produce a change in the cell redox potential while increasing ROS generation in the inflammatory phases (37). This shift in redox state induced the activation of numerous intracellular signaling pathways, such as nucleic acid synthesis, protein synthesis, enzyme activation, and cell cycle progression (34). Furthermore, an increase in ROS levels and, consequently, in oxidative pathways seems to be crucial for the effects of LLLT on mitochondrial activity in the inflammatory phases (32). Our results suggested that LLLT can use the increase in ROS as a cellular signaling pathway to thereby start the tissuerepair process.

Overall, the SOD levels significantly changed in the skin lesions. There was a significant decrease in the nonprotein-SH group levels, caused by the injury during the acute inflammatory phase. However, by day 3 , the antioxidant system showed a skin injury-promoted increase. Treating the lesion with LLLT decreased SOD activity

\section{References}

1. Edsberg LE, Black JM, Goldberg M, McNichol L, Moore L, Sieggreen M. Revised national pressure ulcer advisory panel pressure injury staging system. $J$ Wound Ostomy Cont Nurs 2016; 43: 585-597, doi: 10.1097/WON.000000 0000000281.

2. Brem H, Kirsner RS, Falanga V. Protocol for the successful treatment of venous ulcers. Am J Surg 2004; 188: 1-8, doi: 10.1016/S0002-9610(03)00284-8.

3. Cheng CF, Sahu D, Tsen F, Zhao Z, Fan J, Kim R, et al. A fragment of secreted Hsp90 $\alpha$ carries properties that enable it to accelerate effectively both acute and diabetic wound healing in mice. J Clin Invest 2011; 121: 4348-4361, doi: $10.1172 / \mathrm{JCl} 46475$.

4. Muller MD, Reed AB, Leuenberger UA, Sinoway LI. Physiology in medicine: Peripheral arterial disease. J Appl Physiol 2013; 115: 1219-1226, doi: 10.1152/japplphysiol. 00885.2013. compared to the skin injury in the inflammatory phase. One possible reason for this observed antioxidant depletion may be that the antioxidant system increased the circulating ROS levels. LLLT effectively reduced the decrease in non-protein-SH group levels, and the effects of LLLT on non-protein-SH group levels cemented our understanding of the treatment's actions on cellular systems. Moreover, previous studies have further established that LLLT decreases SOD activity (38).

\section{Conclusion}

Taken together, these results led us to suggest that LLLT accelerated skin tissue repair via a mechanism that modulated increased ROS levels and lipid peroxidation, especially in the early stages of skin injury healing (i.e., during the inflammatory phase). Considering that ROS play a signaling role in cell survival and proliferation, we hypothesize that LLLT can be used as a cellular signaling pathway to increase ROS. In this way, LLLT can decrease the amount of time needed for tissue repair. In order to confirm this hypothesis, further studies are needed to explore the effects of LLLT on mitochondrial activity and the signal transcription of skin cells. This will help elucidate the therapeutic mechanisms of action, while also amplifying and improving clinical applications of this therapeutic approach.

\section{Acknowledgments}

We are thankful to the Brazilian National Council of Technological and Scientific Development (CNPq), Coordenação de Aperfeiçoamento de Pessoal de Nível Superior (CAPES), Brazilian National Institute for Science and Technology (INCT), Programa de Apoio a Núcleos Emergentes (PRONEM), and MCTI/CNPq (472669/20117 and 475896/2012-2) for providing financial assistance for this work.

5. Špoljar S. Differential diagnosis and work up of chronic leg ulcers [in Croatian]. Acta Medica Croatica 2014; 68: 25-30.

6. Pannier $F$, Rabe E. Differential diagnosis of leg ulcers. Phlebology 2013; 28: 55-60, doi: 10.1177/02683555134 77066.

7. Halliwell B. Antioxidants in human health and disease. Annu Rev Nutr 1996; 16: 33-50, doi: 10.1146/annurev.nutr.16. 1.33.

8. Kuffler DP. Photobiomodulation in promoting wound healing: a review. Regen Med 2016; 11: 107-122, doi: 10.2217/ rme.15.82.

9. Järvinen $T A H$, Järvinen $T L N$, Kääriäinen $M$, Kalimo $H$, Järvinen M. Muscle injuries: biology and treatment. Am J Sports Med 2005; 33: 745-764, doi: 10.1177/036354650 5274714

10. Plentz RDM, Stoffel PB, Kolling GJ, Costa ST, Beck C, Signori LU. Hematological changes produced by $1 \mathrm{MHz}$ 
continuous ultrasound, applied during the acute phase of iatrogenic muscle injury in rats. Rev Bras Fisioter 2008; 12, doi: 10.1590/S1413-35552008000600010.

11. Chaves MEA, de Araújo AR, Piancastelli ACC, Pinotti M. Effects of low-power light therapy on wound healing: LASER x LED. An Bras Dermatol 2014; 89: 616-623, doi: 10.1590/ abd1806-4841.20142519.

12. Bossini, PS, Fangel, R, Habenschus, RM, Renno, AC, Benze, B, Zuanon, JA, et al. Low-level laser therapy $(670$ $\mathrm{nm}$ ) on viability of random skin flap in rats. Lasers Med Sci 2009; 24: 209-213, doi: 10.1007/s10103-008-0551-5.

13. Mayer L, Gomes FV, Baraldi CE, Weber JBB, de Oliveira MG. Assessment of LLLT systemic effects on thyroid hormones function after dental titanium implant installation: An experimental rabbit model. Nat Sci 2013; 5: 933-940, doi: 10.4236/ns.2013.58113.

14. Houreld NN, Masha RT, Abrahamse H. Low-intensity laser irradiation at $660 \mathrm{~nm}$ stimulates cytochrome c oxidase in stressed fibroblast cells. Lasers Surg Med 2012; 44: 429434, doi: 10.1002/lsm.22027.

15. Corazza AV, Jorge J, Kurachi C, Bagnato VS. Photobiomodulation on the angiogenesis of skin wounds in rats using different light sources. Photomed Laser Surg 2007; 25: 102-106, doi: 10.1089/pho.2007.2011.

16. Ohkawa $\mathrm{H}$, Ohishi N, Yagi K. Assay for lipid peroxides in animal tissues by thiobarbituric acid reaction. Anal Biochem 1979; 95: 351-358, doi: 10.1016/0003-2697(79)90738-3.

17. Myhre $\mathrm{O}$, Andersen JM, Aarnes $\mathrm{H}$, Fonnum F. Evaluation of the probes $2^{\prime}, 7^{\prime}$-dichlorofluorescin diacetate, luminol, and lucigenin as indicators of reactive species formation. Biochem Pharmacol 2003; 65: 1575-1582, doi: 10.1016/S0006-2952 (03)00083-2.

18. Bernas T, Dobrucki J. Mitochondrial and nonmitochondrial reduction of MTT: Interaction of MTT with TMRE, JC-1, and NAO mitochondrial fluorescent probes. Cytometry 2002; 47: 236-242, doi: 10.1002/cyto. 10080.

19. Misra HP, Fridovich I. The role of superoxide anion in the autoxidation of epinephrine and a simple assay for superoxide dismutase. J Biol Chem 1972; 247: 3170-3175, doi: 10.1016/S0021-9258(19)45228-9.

20. Aebi H. Catalase in vitro. Methods Enzymol 1984; 105: 121-126, doi: 10.1016/S0076-6879(84)05016-3.

21. Ellman GL. Tissue sulfhydryl groups. Arch Biochem Biophys 1959; 82: 70-77, doi: 10.1016/0003-9861(59)90090-6.

22. Boschi ES, Leite CE, Saciura VC, Caberlon E, Lunardelli A, Bitencourt $S$, et al. Anti-inflammatory effects of low-level laser therapy $(660 \mathrm{~nm})$ in the early phase in carrageenaninduced pleurisy in rat. Lasers Surg Med 2008; 40: 500-508, doi: $10.1002 / \mathrm{lsm} .20658$.

23. Machneva TV, Kosmacheva NV, Vladimirov YA, Osipov AN. The effect of low power laser radiation of blue, green, and red ranges on free radical processes in blood of rats with experimental endotoxic shock. Biochem Suppl Ser B Biomed Chem 2012; 6: 237-246, doi: 10.1134/s199075 0812030109.

24. Prabhu V, Rao SBS, Chandra S, Kumar P, Rao L, Guddattu, et al. Spectroscopic and histological evaluation of wound healing progression following Low Level Laser Therapy (LLLT). J Biophotonics 2012; 5: 168-184, doi: 10.1002/ jbio.201100089.
25. Passarella S, Casamassima E, Molinari S, Pastore D, Quagliariello E, Catalano IM, et al. Increase of proton electrochemical potential and ATP synthesis in rat liver mitochondria irradiated in vitro by helium-neon laser. FEBS Lett 1984; 175: 95-99, doi: 10.1016/0014-5793(84)80577-3.

26. Karu T, Pyatibrat L, Kalendo G. Irradiation with $\mathrm{HeNe}$ laser increases ATP level in cells cultivated in vitro. $J$ Photochem Photobiol B 1995; 27: 219-223, doi: 10.1016/1011-1344(94) 07078-3.

27. Giuliani A, Lorenzini L, Gallamini M, Massella A, Giardino L, Calzà L. Low infra red laser light irradiation on cultured neural cells: effects on mitochondria and cell viability after oxidative stress. BMC Complement Altern Med 2009; 9: 8, doi: 10.1186/1472-6882-9-8.

28. Karu TI, Kolyakov SF. Exact action spectra for cellular responses relevant to phototherapy. Photomed Laser Surg 2005; 23: 355-361, doi: 10.1089/pho.2005.23.355.

29. Karu TI, Pyatibrat LV, Kalendo GS. Photobiological modulation of cell attachment via cytochrome c oxidase. Photochem Photobiol Sci 2004; 3: 211-216, doi: 10.1039/b306 126d.

30. Avci P, Gupta GK, Clark J, Wikonkal N, Hamblin MR. Lowlevel laser (light) therapy (LLLT) for treatment of hair loss. Lasers Surg Med 2014; 46: 144-151, doi: 10.1002/lsm.22 170.

31. Volpato LER, de Oliveira RC, Espinosa MM, Bagnato VS, Machado MAAM. Viability of fibroblasts cultured under nutritional stress irradiated with red laser, infrared laser, and red light-emitting diode. J Biomed Opt 2011; 16: 075004, doi: 10.1117/1.3602850.

32. Missiroli S, Genovese I, Perrone M, Vezzani B, Vitto VAM, Giorgi $C$. The role of mitochondria in inflammation: from cancer to neurodegenerative disorders. J Clin Med 2020; 9: 740, doi: $10.3390 / j \mathrm{~cm} 9030740$.

33. Gupta A, Dai T, Hamblin MR. Effect of red and near-infrared wavelengths on low-level laser (light) therapy-induced healing of partial-thickness dermal abrasion in mice. Lasers Med Sci 2014; 29: 257-265, doi: 10.1007/s10103-013-1319-0.

34. Farivar S, Malekshahabi T, Shiari R. Biological effects of low level laser therapy. J Lasers Med Sci 2014; 5: 58-62, doi: 10.22037/2010.v5i2.5540.

35. Cauwels A, Rogge E, Vandendriessche B, Shiva S, Brouckaert P. Extracellular ATP drives systemic inflammation, tissue damage and mortality. Cell Death Dis 2014; 5: e1102, doi: 10.1038/cddis.2014.70.

36. Puntel GO, Carvalho NR, Amaral GP, Lobato LD, Silveira SO, Daubermann MF, et al. Therapeutic cold: an effective kind to modulate the oxidative damage resulting of a skeletal muscle contusion. Free Radic Res 2011; 45: 133-146, doi: 10.3109/10715762.2010.517252.

37. Luo L, Sun Z, Zhang L, Li X, Dong Y, Liu TCY. Effects of lowlevel laser therapy on ROS homeostasis and expression of IGF-1 and TGF- $\beta 1$ in skeletal muscle during the repair process. Lasers Med Sci 28 2013; 28: 725-734, doi: 10.1007/s10103-012-1133-0.

38. Silveira PCL, da Silva LA, Fraga DB, Freitas TP, Streck EL, Pinho R. Evaluation of mitochondrial respiratory chain activity in muscle healing by low-level laser therapy. J Photochem Photobiol B 2009; 95: 89-92, doi: 10.1016/ j.jphotobiol.2009.01.004. 